\title{
LAS CONSTRUCCIONES CIFRADAS EN LA NARRATIVA CUZQUEÑA COPÉ
}

\author{
Un estudio preliminar de 1979 hasta el presente
}

Mario Ramos Tacca ${ }^{I}$

\section{RESUMEN}

El siguiente ensayo analiza y describe el universo narrativo de las construcciones cifradas en una selecta compilación de trece cuentos escritos por reconocidos escritores cuzqueños que obtuvieron importantes galardones en los diferentes certámenes del Premio Copé de Cuento desde 1979. Por lo tanto, se trata de un estudio que aborda y examina la presencia de la técnica como parte de un procedimiento renovado que caracteriza la condición del cuento moderno en Hispanoamérica. Así mismo, se propone dar cuenta e influir en las nuevas generaciones sobre la relevante posición que ocupan las letras cuzqueñas dentro del cosmos literario nacional e internacional.

PALABRAS CLAVE: Construcción cifrada, narrativa, técnica, premio.

\section{ABSTRACT}

The following essay analyses and describes the narrative universe of coded constructions in a select compilation of

1 M.Sc. Lingüística Andina y Educación. Docente de la Universidad Nacional de San Antonio Abad del Cusco. Departamento Académico de Lingüistica.E-mail:mario.ramos@unsaac.edu.pe 
thirteen short stories written by renowned cuzquenian writers who won important awards in the different contests of "Premio Copé de Cuento" since 1979. Therefore, it is a study that approaches and examine the presence of encoded constructions in the tales as part of a renewed technique that characterizes the condition of the modern short stories in Latin America. Equally, it is proposed to give a reason and influence in new generations about the relevant position that cuzquenian letters fill in national and international literary universe.

KEYWORDS: Encrypted construction, narrative, technique, prize.

Ce sabe que en el panorama de la $\checkmark$ literatura cuzqueña, se han escrito varios tratados y estudios dedicados a auscultar la narración desde diversas perspectivas. Los enfoques de muchos de ellos, se constituye en un prolífico aporte que abre el camino a sucesivos estudios hermenéuticos en el género narrativo. Sin embargo, el presente estudio es una modesta contribución que llega a complementar ese amplio universo de enfoques y expone un abordaje dedicado exclusivamente, al tópico de los cuentos premiados en el certamen Copé de Cuento.

En consecuencia, cuando a inicios del presente año en el Suplemento Cultural Inkari del diario El Sol del Cuzco se publicó el artículo: Narrativa Cuzqueña Copé, también nació la idea de que el minúsculo texto debía convertirse en el exponente de un estudio más amplio y digno de las manifestaciones artísticas de un pueblo que es heredero de un legado cultural incomparable que se desarrolla sobre la base de un profundo arraigo literario desde tiempos inmemoriales.

Así, lo percibía en su momento, el exégeta cuzqueño Rubén Sueldo Guevara, quien en su estudio sobre los Narradores Cuzqueños, enfatiza que los escritores son, en alguna medida, herederos de la capacidad creadora aborigen; que la prosa de ficción se sustenta en esa otra anónima, oral, que se proyecta desde el incario. Empero, la actividad creadora no comienza con la llegada de los españoles que trajeron su escritura y su lengua, sino que es congénita a las civilizaciones que se desarrollaron en este territorio desde tiempos milenarios muy particularmente en el Imperio de los Incas. (1984, p. 10).

\section{LAS CONSTRUCCIONES CIFRADAS}

La compleja operación técnica que experimentan los escritores a la hora de estructurar una impactante historia, es motivo de permanentes interrogantes por parte de lectores, críticos y analistas escrupulosos que se aventuran a descifrar la estructura de un cuento: ¿cómo es posible que al concluir la lectura de un cuento, uno no pueda advertir la presencia de otra historia paralela que el narrador arteramente escondió desde un inicio? ¿Se trata de un embuste del narrador? ¿Cómo se llama ese procedimiento? En términos literarios se le conoce con el nombre de "historia o construcción cifrada".

Un primer punto de referencia lo expone Piglia (1986) quien en Formas Breves, capítulo Tesis sobre el cuento plantea una importante tesis: Un cuento siempre cuenta dos historias. Entonces, ¿la narrativa cuzqueña presenta estos artificios?

El propósito de este enfoque preliminar es confirmar la presencia de la técnica literaria aludida en los cuentos que fueron premiados en el certamen Copé. Para ello, al dar cuenta de los procedimientos descritos, se sigue el esquema analítico-descriptivo que a continuación se expone: el primer plano, cuenta la historia $1(\ldots)$, el segundo plano, construye en secreto la historia $2(\ldots)$

Ampliando, el mismo autor en el punto II del estudio referido, enfatiza: "El arte del cuentista consiste en saber cifrar la historia 2 en los intersticios de la historia 1 . Un relato visible esconde un relato secreto, narrado de un modo elíptico y fragmentario" argumentos que explican de modo categórico los entramados técnicos de lo que se viene sosteniendo.

De otro lado, corroborando al respecto, Vargas Llosa (1997) en las recomendaciones epistolares que le hace llegar a un joven novelista sobre el dato oculto, explica:

En efecto, no sería exagerado decir que las mejores historias de Hemingway están llenas de silencios significativos, dato $s$ escamoteados por un astuto narrador que se las arregla para que las informaciones que 
calla sean sin embargo locuaces y azucen la imaginación del lector, de modo que éste tenga que llenar aquellos blancos de la historia con hipótesis y conjeturas de su propia cosecha. (p. 846)

Es más, las tensiones que atrapan al lector desde un inicio, no solo implica esconder datos, también implica poner en juego intrigas y tramas que tejen una compleja estructura que linda entre lo explícito e implícito de inicio a fin.

Quizá esa complejidad radica en lo que Brescia (2014) considera un elemento fundamental dentro del nuevo cuento latinoamericano. Para ello, refiere un sesudo prólogo que en 1964, Borges dedica a la obra de María Esther Vásquez y cita un pasaje referido a Allan Poe que sirve de contexto al tema que se viene explicando:

Edgar Allan Poe sostenía que todo cuento debe escribirse para el último párrafo o acaso para la última línea; esta exigencia puede ser una exageración, pero es la exageración o simplificación de un hecho indudable. Quiere decir que un prefijado desenlace debe ordenar las vicisitudes de una fábula. Ya que el lector de nuestro tiempo es también un crítico, un hombre que conoce, y prevé, los artificios literarios, el cuento deberá constar de dos argumentos; uno, falso, que vagamente se indica, y otro, el auténtico, que se mantendrá en secreto hasta el fin. (p. 73)

De acuerdo con la cita, se puede entender que Borges intenta resaltar dos aspectos básicos de la narración moderna: "las condiciones de lectura y la necesidad de trabajar con dos argumentos". Según ello, la función del lector y la doble historia serían los pilares del modo de lectura introducidos por Borges dentro de la percepción del cuento e hilos conductores en una determinada historia.

Estos elementos fundamentales de las historias modernas hacen ver que el cuento adquiere la relevancia requerida cuando en su estructura interna y externa presentan una construcción cifrada paralela que, en realidad no se narra, pero que en el desenlace de la historia aparece como un elemento subliminal complementario que remata todo el contenido de la narración.

En ese sentido, Sueldo (1984) en el contexto cuzqueño, haciendo alusión a los cambios experimentados por la narrativa, percibe la idea de que con la llegada de los tiempos modernos se inaugura un nuevo ciclo en el cuento cuzqueño, incorporando técnicas, procedimientos y temática acordes con el momento. Y, asimismo, la actividad literaria toma nuevos impulsos y rumbos.

\section{EL RELATO CIFRADO Y EL CUENTO COPÉ}

El Premio Copé de Cuento de la Corporación Petróleos del Perú, es sin lugar a dudas, el certamen literario más codiciado de los últimos tiempos. Desde que en 1979 viera la luz su primera convocatoria, no ha dejado de atraer la atención de cientos y cientos de escritores que gracias a su participación en las diferentes convocatorias, han desfilado por la palestra de la consagración ocupando, desde entonces, lugares privilegiados dentro de la narrativa peruana e hispanoamericana.

La sobresaliente presencia de escritores cuzqueños herederos de una larga tradición de prosistas encumbrados como Garcilaso de la Vega, Narciso Aréstegui, Clorinda Matto y otros, se hizo notar desde un principio. Es así que entre los primeros galardonados se tiene a un cuzqueño que hizo la proeza de hacerse del primer lugar en la I Bienal de Cuento Copé del año 1979. Washington Delgado (Cuzco, 1927 - Lima, 2003) quien obtuvo el Copé de Oro con el cuento "La muerte del doctor Octavio Aguilar". Una historia de ficción cuya historia 1 (relata las desavenencias transcurridas entre la vida y la muerte que aquejan a un añejo catedrático de literatura en los claustros de una universidad capitalina). La historia cifrada 2 (narra las actividades políticas del doctor Octavio Aguilar hasta ser elegido Decano).

En el certamen del año 1979, también aparece la figura de Carlos A. Bravo Espinoza (Cuzco, 1945) quien con el cuento "El gerente" obtiene una Mención Honrosa. Y a decir de los planos narrativos, se observa que la historia 1 (relata los audaces embustes idílicos de 
Gastón, el gerente) y la historia cifrada 2 (revela la verdadera ocupación del protagonista).

Desde entonces, han transcurrido diecinueve convocatorias y el proceso evolutivo de las letras cuzqueñas siguió su caudaloso cauce y muestra su ostensible presencia a través de narradores que pertenecen a distintas generaciones que haciendo gala de su magistral creatividad y técnica para el cuento, ocuparon expectantes lugares en las diferentes bienales.

Así, el admirable talento de Enrique Rosas Paravicino (Ocongate, Cuzco, 1948) queda consolidada en 1985 y se da a conocer dentro de los escritores nacionales con "Al filo del rayo". Relato cuyo contenido 1 (aborda la problemática político social desatada por el grupo Sendero Luminoso en la zona andina de Urcos) y la historia cifrada 2 (relata el develamiento de la verdadera identidad de los implicados por parte del narrador personaje). Con esta historia, Rosas, logra ubicarse como uno de los finalistas de la Cuarta Bienal del Premio Copé.

Posteriormente, Rosas repite la escena en la Bienal de 1987 con "Temporal en la cuesta de los difuntos" que en el primer plano (relata las peripecias de un grupo de viajeros que salen de Madre de Dios hacia el Cuzco en un camión Volvo). El plano 2 (narra la idiosincrasia del poblador andino expresada en el acontecimiento del nacimiento de un niño en pleno viaje, pues así como hay vidas que se van, hay vidas que vienen).

Luego de un silencio catártico, una nueva oleada de narradores cuzqueños se posiciona en los peldaños más expectantes del concurso. En 1992, aparece la vigorosa pluma de Luis Nieto Degregori (Cuzco, 1955), quien con una narración de corte histórico basado en la vida de Mariano Túpac Amaru: "María Nieves" se alza con el Copé de Oro de la VII Bienal del mencionado premio. El relato en un primer plano (narra las aventuras amorosas de Mariano Túpac Amaru y María Nieves) El plano 2 (el revanchismo, la venganza perpetrada por un obsesionado corregidor cegado por los celos).
La siguiente convocatoria, el Copé de Plata de la VIII Bienal de 1994, queda reservado para Jaime Pantigozo Montes (Cuzco, 1946), quien logra ubicarse en el segundo lugar con "El canto del tuco". El relato 1 (refleja los conflictos sociales que azotaron el Sur del país allá por la década del 90 retratado en Apolinario, joven dirigente comunal de Yuraqkancha), el plano 2 (describe el castigo que a cambio recibe Apolinario por llevar una vida voluble e inmoral).

Del mismo modo, en la Bienal de 1996, Ángel Avendaño Farfán (Cuzco, 1937), repite el Copé de Plata con la narración "Libreta de campo". Historia cuyo primer plano 1 (relata las incidencias de una visita de estudios al Kiswarkancha por un grupo de estudiantes de arqueología y su profesor. El narrador personaje, devela los misterios del lugar, junto a los sucesos históricos de la muerte de Diego de Almagro por los pizarristas en el Cuzco). La historia 2 (relata los desenlaces amorosos secretos y los estudios de campo que protagonizan un profesor y una alumna de la universidad).

En 1998, Enrique Rosas Paravicino, nuevamente se ubica entre los finalistas de la XI Bienal con "El fantasma es el otro". Historia que en el plano 1 (narra las incidencias de un asalto perpetrado a un banco en Lima por un grupo de jóvenes revolucionarios con el fin de subsidiar el levantamiento de Hugo Blanco en Chaupimayo, La Convención, Cuzco) y la historia 2 (relata el desenlace por el que atraviesa el personaje Ranguel y Martín Villamonte, luego que sus vidas se vuelven a cruzar después de veintidós años en una agencia bancaria. Se puede decir que se cumple la frase: quien a hierro mata, a hierro muere).

En la XII Bienal de Cuento 2002, Pedro Ugarte Valdivia (Cuzco, 1951) se ubica como finalista con el cuento "El lienzo". Historia que en el plano 1 (narra la experimentación fantástica y las visiones oníricas de un personaje implicado en una historia familiar enigmática que en el pasado fueron retratados en un lienzo), el plano 2 (revela la verdadera razón de la existencia del lienzo y su significado para el 
joven soñador). Igualmente, Jaime Pantigozo Montes, logra una ubicación importante como finalista con la narración "El día de la madre", cuya historia 1 (narra la historia surrealista y autobiográfica del narrador personaje que sostiene un diálogo de corte frustrado con Esteban Quiroz, durante un viaje y contada con una técnica renovada dentro de los cánones de la moderna narrativa urbana). El plano 2 (relata el factor psicológico de desahogo que experimenta una joven madre frustrada por el destino).

La XIV Bienal de Cuento Premio Copé 2006 trae las voces altisonantes de una nueva generación de narradores cuzqueños que incursionan con fuerza telúrica en el panorama literario internacional. Gabriela Caballero (Cuzco, 1977) y Arturo Mosqueira (Cuzco, 1975) se ubican como los mejores finalistas del certamen de ese año, con los cuentos: "La metamorfosis de Alejandra", narración cuyo plano 1 (describe desde la perspectiva psicológica la esquizofrenia que aqueja a una muchacha y que transforma su conducta cada vez que embiste la crisis). La historia 2 (relata la consolidación del estado psicopatológico de Alejandra que poco a poco se va apartando definitivamente del mundo real). La parte más débil de la cuerda, en el plano 1 (relata las experiencias y las vivencias de los migrantes provincianos en la ciudad capital cuando se enfrentan a situaciones complicadas del mundo laboral). La historia 2 (cuenta el desenlace que experimenta el narrador personaje que es atormentado por los actos de injusticia y corrupción del cual es víctima debido a su sólida formación personal con base en los principios e ideales éticos).

A partir de los siguientes años, la XV Bienal del Premio Copé experimenta cambios y ampliaciones en su organización. Aparece, esta vez, con el rótulo de "Premio Copé Internacional 2008" en el que emerge, nuevamente, la presencia cuzqueña con Pedro Ugarte Valdivia, quien se consagra con el Premio Copé de Oro por el cuento "Relámpago inmóvil", cuyo plano 1 (relata el despliegue de acontecimientos en el que Francisco Quesnay y un objeto -el disco áureo sideral- se mezclan con elementos narrativos de lo fantástico y real maravilloso). El elemento 2 (narra los acontecimientos de la guerra napoleónica en Waterloo y el personaje que extravía el disco y la verdadera ubicación del objeto sideral en la actualidad).

A modo de conclusión, es necesario recalcar que este ensayo tiene entre otras intenciones ser la expresión de un merecido tributo a la obra de los principales exponentes de la narrativa regional $\mathrm{y}$, de ese modo, evidenciar que Cuzco es cuna de una fértil tradición literaria expresada en sus valores artístico-literarios, a través de los cuales, se percibe la vigencia y trayectoria de las letras cuzqueñas como un irrefutable aporte a la literatura peruana.

Que las letras cuzqueñas permanezcan esplendorosas en la memoria del peruano desafiando los límites del inexorable transcurso del tiempo.

\section{REFERENCIAS}

Brescia, P. (2014). Asedios a la forma: Teorías (Clásicas y nuevas) del cuento. Perífrasis. Revista de Literatura, Teoría y Crítica, vol. 5, núm. 9. Bogotá, enero - junio 2014, 96 pp. 65-78. Consulta: 23 de mayo de 2017. Disponible en: http://www.redalyc.org/articulo.oa?id=478147217007

Cox, M. R. (2004). Cincuenta años de narrativa andina. Desde los años 50 hasta el presente. Perú: Editorial San Marcos.

Ediciones Copé. (1994). María Nieves y los cuentos ganadores del Premio Copé 1992. Lima: PETROPERU S.A.

Ediciones Copé. (1995). Cuando las últimas luces se hayan apagado y los cuentos ganadores del Premio Copé 1994. Lima: PETROPERU S.A.

Ediciones Copé. (2001). El cuento peruano, 1990 - 2000. Lima: PETROPERU S.A.

Ediciones Copé. (2001). Lápices y los cuentos ganadores y finalistas de la XI Bienal de Cuento del 'Premio Copé 2000”. Lima: PETROPERU S.A.

Ediciones Copé. (2005). Guitarra de Palisandro y los cuentos ganadores y finalistas de la XII Bienal de Cuento "Premio Copé 2002". Lima: PETROPERU S.A.

Ediciones Copé. (2007). El mestizo de las Alpujarras y los cuentos ganadores y finalistas de la XVI Bienal de Cuento "Premio Copé 2006". Lima: PETROPERU S.A.

Pantoja, M. (2005) Halcones y serpientes. El cuento cusqueño del siglo XX. Lima: Editorial San Marcos.

Petróleos del Perú. (2017). Bienal de Cuento. Recuperado de: http:/www2.petroperu.com.pe/gestioncultural/premio/ premio-cope-2016/

Piglia, R. (1986). Formas breves. Buenos Aires: Editorial Anagrama. Ugarte, P. (2016). Relámpago Inmóvil. Lima: Ediciones Altazor. Vargas, M. (1997). Cartas a un joven novelista. Madrid: Alfaguara. 
